\title{
Research and development of equipment management information system in rubber manufacturing enterprises based on BPR
}

\author{
Xian-Zhao JIA ${ }^{1, \text { a }}$, Rui-Rui MA ${ }^{2, b}$ \\ ${ }^{1}$ Henan University of Science and Technology, Luoyang, Henan, 471003, China \\ ${ }^{2}$ Henan University of Science and Technology, Luoyang, Henan, 471003, China \\ a jiaxzh@126.com, b1033689440@qq.com
}

Keywords: Equipment management; Information system; Process reengineering; B/S Structure.

\begin{abstract}
There are many problems in the current process of equipment management of a rubber manufacturing enterprises. On the basis of some advanced methods of equipment management at home and abroad. To modify the unreasonable part of the existing processes through using the advanced technology of BPR. Analysis the equipment management process of before and after qualitatively and quantitatively. On the basis of that, design a reasonable new equipment management information system based on $\mathrm{B} / \mathrm{S}$ structure. Realize the system by using the asp technology. Finally, complete information management of the equipment in the enterprise.
\end{abstract}

\section{Introduction}

With the vigorous development of the industry, the rubber production enterprises developed rapidly. Equipment management is the important part of enterprise management. The level of equipment management reflects the overall level and comprehensive strength of enterprises. At present, equipment management in the rubber production enterprise is still in a very backward state of confusion. Chaotic management process caused the management process of equipment management is not timely. The storage of relevant data of equipments is still in the level of manual bookkeeping, information is not shared and query the information of equipment management is not convenient. So, to strengthen the management of equipment is very important. In this paper, the research aims to improve the management process of the whole life cycle from the purchase to scrap of the equipment. Make the management of equipments more clearly and realize the whole life cycle of information management of equipment. Enable managers to get rid of the style of manual bookkeeping, Improve the management efficiency of equipment. Avoid the loss of information in the process, etc. Do the management timely ${ }^{[1-2]}$.

\section{Equipment management process optimization}

Through investigation and research of the enterprise many times, found that the management process of equipment is very unreasonable. From start to buy the equipment to scrap eventually, there is not a system management process to manage the equipment. At present, firms are not someone who's in charge of in equipment management. Basically rely on the leadership of the subjective consciousness. The management of related management personnel is not in a timely manner, unreasonable purchasing plan limits the production efficiency. Take up a large amount of operating funds, information is chaotic, information is not updated in a timely manner, information is not shared and loss is very serious, caused enterprises exist a lot of unnecessary loss. Directly affect the profits of the enterprise.

According to the demand for the development of enterprises and combining with the actual situation of the enterprise. Design a set of equipment management process. It is suitable to the enterprise. The equipment management process covers all the problem of equipment management in whole life cycle of equipment. Equipment management personnel all do their job. The rigorous management pattern to make equipment management more efficient. The productivity of enterprises 
improved. Figure 2 is the process of full life cycle of equipment management ${ }^{[2]}$.

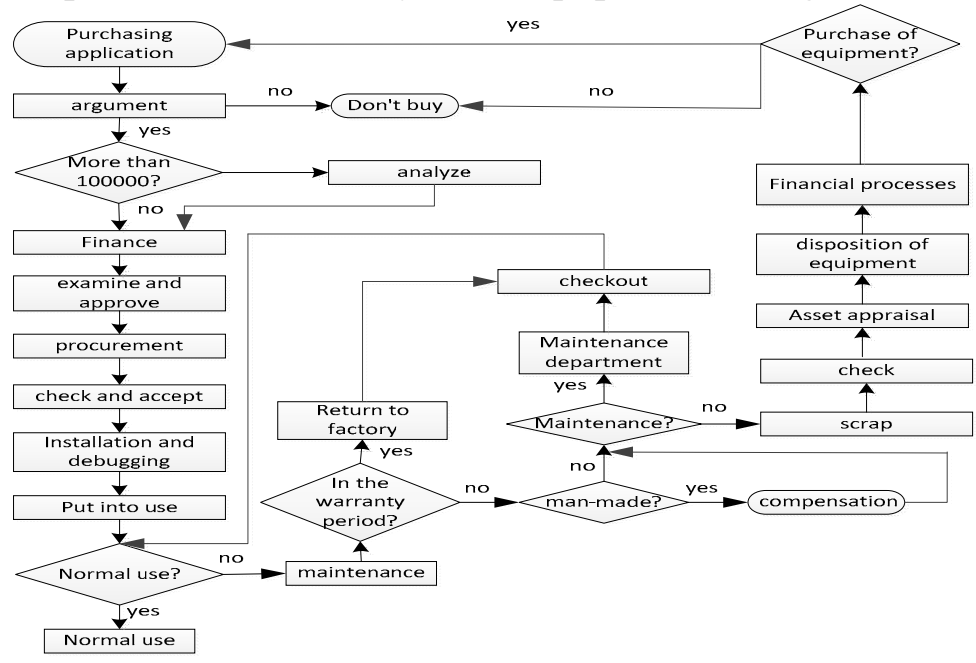

Fig.1 Process of equipment management of full life cycle

\section{Quantitative analysis of the equipment management process}

Do the qualitative analysis of the original management process and the optimized management process is not enough. There are a large number of subjective factors. Here, by building the business process quality comprehensive evaluation index system. To score before and after the optimization of business process using Delphi expert evaluation method. Use the analytic hierarchy process (AHP) to do quantitative analysis on equipment management process. Get results based on MATLAB.

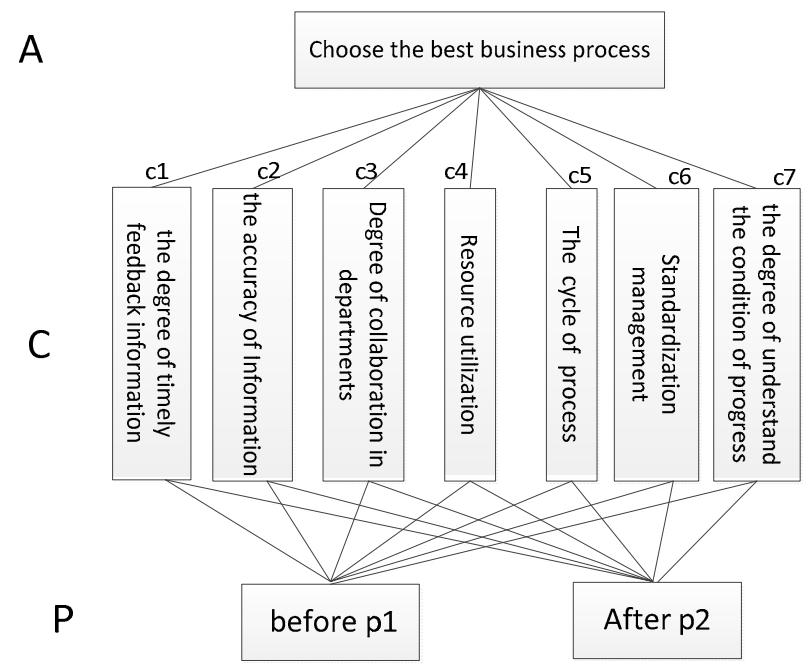

Fig.2 The model of hierarchical analysis

Established the A - C judgment matrix and c1-p...c7-p judgment matrix, through $\overline{w_{i}}=\sqrt[n]{\prod_{j=1}^{n} b_{i j}}$, $w_{i}=\frac{\overline{w_{i}}}{\sum_{i=1}^{n} \overline{w_{i}}}, i=1,2, \ldots, n$ get the total sorting table.

$C R=\frac{C I}{C R} C R=0.0242<0.1$ 
Table. 1 the total sorting table

\begin{tabular}{|l|l|l|l|l|l|l|l|l|l|}
\hline \multirow{2}{*}{$\begin{array}{r}\text { P } \\
\text { R }\end{array}$} & C1 & C2 & C3 & C4 & C5 & C6 & C7 & weight & ranking \\
\cline { 2 - 8 } & 0.1595 & 0.2410 & 0.0316 & 0.3514 & 0.0448 & 0.1040 & 0.0678 & & \\
\hline P1 & 0.2500 & 0.3333 & 0.3333 & 0.2500 & 0.7500 & 0.3333 & 0.2000 & 0.2716 & 2 \\
\cline { 1 - 8 } P2 & 0.7500 & 0.6667 & 0.6667 & 0.7500 & 0.2500 & 0.6667 & 0.8000 & 0.7284 & 1 \\
\hline
\end{tabular}

\section{System requirements analysis}

The demand of the enterprise is the foundation of the system design. The design of the system to keep up with the needs of the enterprises. At present enterprise has the following several requirements for the function of the system:

- The basic information of the equipment need to input in the system. Realize the function of query, print and export, delete, modify, and other functions, realization of information network and information sharing.

- Dynamic management the information of view data of the key equipment, technical parameters, running state, downtime and time to repair and so on.

- The state of the equipment management, for example, the data of technology, fault information, running state and so on, achieving that information management. Easy to query and print.

- Manage the plan of the repair, update and transformation of the equipment by using the computer. Facilitate query schedule and project information.

- Input the information of the lubrication chart and lubrication oil of equipment in the system to facilitate the query.

\section{System function modules}

In order to meet the needs of enterprises and enterprises demand for system functions. The system set up nine major function module.

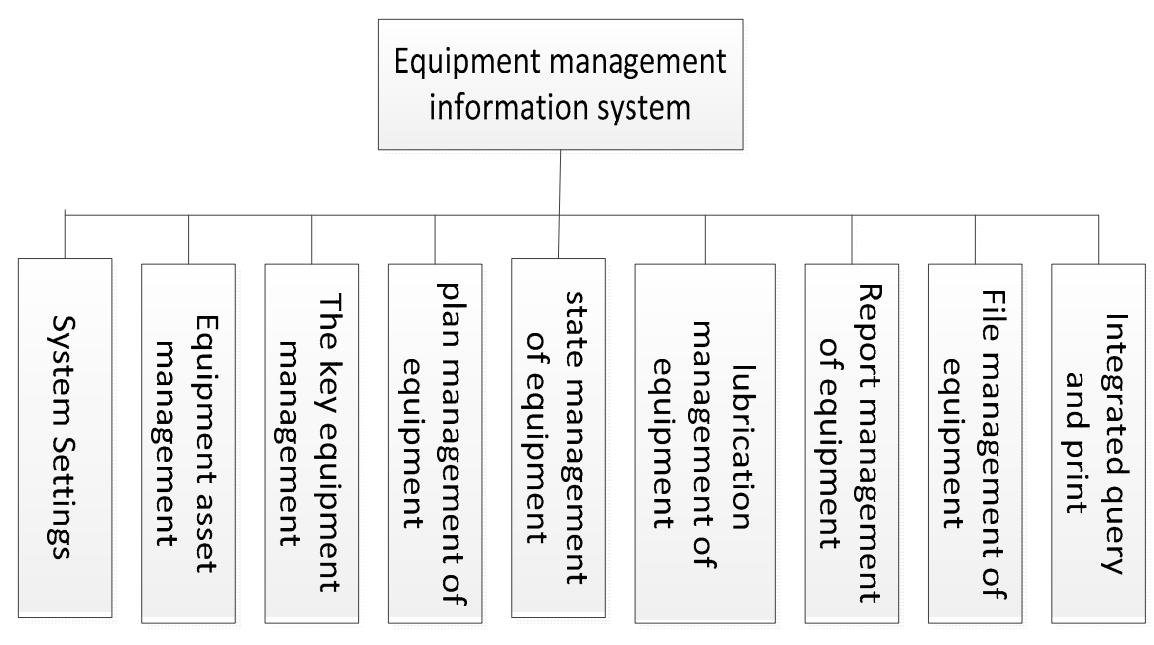

Fig.3 Functional modules of management information system of equipment

\section{Database design}

The design of $\mathrm{E}-\mathrm{R}$ diagram is the key of the database design. E-R diagram is used to describe the conceptual model. 


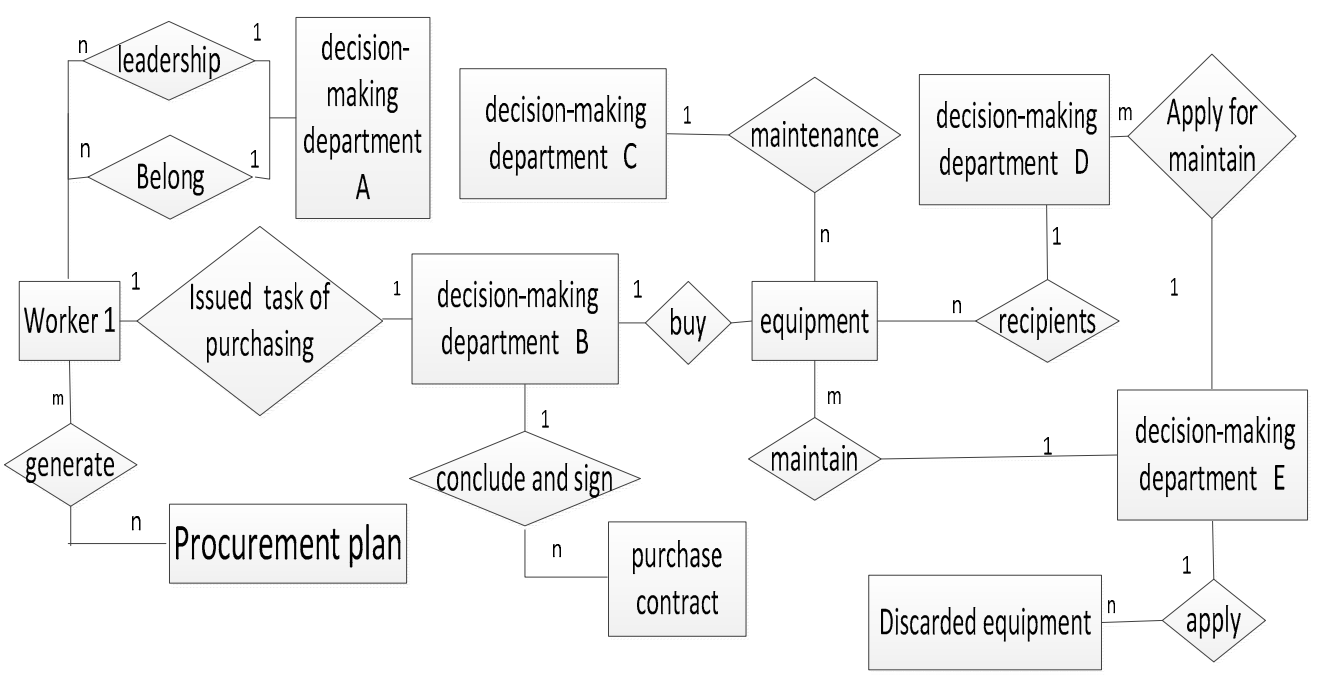

Fig.4 E-R diagram of management information system of equipment

\section{System function realization}

The system use Visual Studio2012 development environment. It was developed by Microsoft .Passed redesigned interface make the work process is greatly simplified. Provides access to common tools of shortcuts. According to the situation of the enterprise, the database system use SQL Server $2005^{[3]}$. The system is a relatively large and complex system. It is composed of many different interface. Here, select the typical home page of the system to introduce. A bar on the right is the main function modules of the equipment management information system. Realize the all kinds of information of equipment to inquire. The system set up the function of print, export and composite query. Implements the transform of the electronic and print information. Integrated query function to achieve the detailed information query of the equipment. The system realizes the informatization of the equipment management process.

\section{Conclusions}

In this paper, analyzed the management status of the rubber production enterprise, find out the present problems of the enterprise. Developed a set of equipment management information system based on $\mathrm{B} / \mathrm{S}$ architecture suitable for the enterprise. The system greatly improved the efficiency of the enterprise to equipment management, realized the full life cycle of equipment management and information management. Make equipment management personnel to get rid of the cumbersome manual bookkeeping, to realize the information sharing.

\section{References}

[1] José Antonio Pérez-Méndez,Ángel Machado-Cabezas. Relationship between management information systems and corporate performance[J]. Revista de Contabilidad,2014.

[2] Madiha Shah. Impact of Management Information Systems (MIS) on School Administration: What the Literature Says[J]. Procedia - Social and Behavioral Sciences,2014,116.

[3] S. M.Wazed Ali. Strategic Requirements of Higher Education Management Information System[J]. Collnet Journal of Scientometrics and Information Management,2011,52.

[4] Mohammad Hossein Moshref Javadi,Mahboubeh Delshad Dastjerdia. Evaluation effect of management information system implementation on personnel resistance causes in Isfahan power plant management corporation in Iran[J]. Procedia Computer Science,2011,3.

[5] S.M.Wazed Ali.Strategic Requirements of Higher Education Management Information System[J]. Collnet Journal of Scientometrics and Information Management,2011,52. 